the calorimeter would differentiate between such small variations in the inert material, the ash and water.

Tabulating the results with reference to these inert materials and giving simply the calorimetric reading for each we have:

\begin{tabular}{|c|c|c|}
\hline No. & $\begin{array}{c}\text { Total of water and ash. } \\
\text { per ceut. }\end{array}$ & B. $\mathrm{r}, \mathrm{t}$. \\
\hline 216 & 5.79 & 12,214 \\
\hline 217 & $=1.80$ & 12,286 \\
\hline 218 & 9.87 & I 2,924 \\
\hline 220 & II .45 & .2 .345 \\
\hline $22 I$ & I 4.02 & 12,056 \\
\hline
\end{tabular}

(c) It has already been mentioned but attention should again be called to the fact that with the calorimeter it is necessary to operate on the oven-dried sample for the reason that the water, if left in the sample, gives off heat $i_{1}$ combining witl the chemical; hence, a gram sample is weighed and dried in the oven or if the per cent. of moisture is known, an oven-dried sample may be weighed out, making allowance for the water. No other conditions vary the restalts. About I7 times the weight of coal is the best amount of peroxide to insure complete combustion but variations from if to 20 times the amount do not appreciably vary the results. Indeed with careful work and a good thermometer the instrument repeats its own results fully as closely as the bomb calorimeters. The usual practice, moreover, has been to work with half-gram samples, using a measured quantity, -8 to 9 grams of peroxide. With a suitable roon and reasonable precautions as to temperature of both room and water employed, exceedingly constant and satisfactory results may be obtained which should vary less than 0.5 per cent. from the best figure obtainable with a standard instrument.

UNIVERSITY OF ILLINOIS.

URBANA, ILL.

[CONTRIBUTIONS FROM THE HAVEMEYER LABORATORIES OF COLUMBIA UNIVERSITY, No. 28.]

\title{
ON THE DETERIINATION OF PHOSPHORIC ACID AS PHOSPHOMOLYBDIC ANHYDRIDE.
}

BY H. C. SHERMAN AND HENRY ST. JOHN HYDE. Received July 23.1900 .

\begin{abstract}
ATHOUGH a great amount of work has been done in this A country upon the subject of phosphorus determination, practically no attention seems to have been given to methods
\end{abstract}


which involve the ignition of ammonium phosphomolybdate and weighing of the residue. A given weight of phosphoric acid yields about sixteen times as much phosphomolybdic anhydride as magnesium pyrophosphate, and the "yellow precipitate can be ignited much more quickly and apparently with quite as definite results as it can be dried. It seems strange, therefore, that less attention has been given to this than to the other rapid gravimetric methods.

The first attempt to determine phosphoric acid as phosphomolybdic anhydride was probably that of Meineke. ${ }^{1}$ The phosphate was precipitated by means of the ordinary acid molybdate reagent from a solution containing 20 to 25 per cent. of ammonium nitrate, heated to $50^{\circ}-60^{\circ}$ and vigorously stirred. After washing with a weakly acid solution of ammonium nitrate, the precipitate was heated below redness for fifteen minutes. The residue was believed to be of constant composition and to it was assigned the formula $\mathrm{P}_{2} \mathrm{O}_{b} \cdot \mathrm{Mo}_{24} \mathrm{O}_{68}$.

Hanamann ${ }^{2}$ about ten years later published a method very similar to that of Meineke but recommended that the precipitation be made at room temperature.

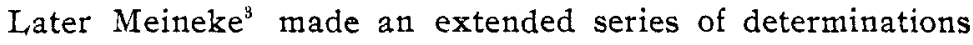
on solutions of pure phosphates from the average of which he calculated the percentage of $\mathrm{P}_{2} \mathrm{O}_{5}$ in the residue to be 3.949 per cent., agreeing well with the formula, $\mathrm{P}_{2} \mathrm{O}_{5} .24 \mathrm{MoO}_{3}$. He recommended that in the presence of a little iron the precipitation be carried out at $50^{\circ}$ in the presence of 5 per cent. of ammonium nitrate, using the ordinary acid molybdate solution while if the solution contained much iron at least ro per cent. of ammonium nitrate and 5 to ro per cent. of strong nitric acid should be present and the precipitation carried out at a higher temperature. Good results are reported on two samples of phosphate.

Woy ${ }^{4}$ developed the following method and applied it to a variety of technical products :

Reagents.-(I) A 3 per cent. solution of ammonium molybdate; (2) ammonium nitrate solution-340 grams per liter; (3) nitric acid of I.I53 sp. gr.; (4) wash solution containing

1 Reperi. anal. Chem., 5, 153 (1885); Zischr. anal Chem., 26, 636 (1887).

2 Chem. Ztg., 19, 553 (1895).

I Ibid., 20, $\operatorname{co8}(1896)$.

4 Ibid., 21, 44I and 469 (I897). 
200 grams ammonium nitrate and $160 \mathrm{cc}$. of nitric acid in 4 liters of water.

Procedure. -To an aliquot part of the solution corresponding to 0.5 gram substance, add $30 \mathrm{cc}$. ammonium nitrate solution and ro to $20 \mathrm{cc}$. of the nitric acid and heat until bubbles commence to rise, then add the necessary quantity of molybdate solution heated to the same degree (about $80^{\circ}$ in our experiments). The reagent is run into the middle of the solution which is kept in motion during the operation. After fifteen minutes when the precipitate has settled, the solution is decanted through a porcelain Gooch crucible, the precipitate washed by decantation with $50 \mathrm{cc}$. of the wash solution and then dissolved in the beaker in dilute ammonia and reprecipitated by adding hot nitric acid, drop by drop, stirring or shaking the solution. Filter on the porcelain Gooch crucible and wash with the hot wash solution. Finally place the porcelain crucible inside of a nickel crucible and heat until the bottom of the latter is dull red. After fifteen minutes the precipitate is transformed into $\mathrm{P}_{2} \mathrm{O}_{5} .24 \mathrm{MoO}_{3}$.

Pellet ${ }^{1}$ considers the second precipitation of ammonium phosphomolybdate recommended by Woy to be unnecessary. Having seen only a brief abstract of his paper we do not know the nature of the experiments on which his conclusion is based.

Hanamann ${ }^{2}$ suggests that contamination with silica is best avoided by carrying out the precipitation at a low temperature and in the presence of considerable free nitric acid.

Some preliminary trials with microcosmic salt solutions having given results quite favorable to Woy's method whether with or without a second precipitation, we were led to compare on a number of samples: (I) The well-known molybdate-magnesia method carried out according to the directions of the Association of Official Agricultural Chemists and here called the official method; (2) Woy's method as published; (3) Woy's method, omitting the second precipitation of ammonium phosphomolybdate. The samples tested were not only " mixed" fertilizers but nearly all of them were "composites" so that' together they represent a large variety of fertilizer materials.

1 Rev. Chim. Analyt. Appl., v. (20), 405; Abs. Analyst, 23, 25 (1898).

2 Ztschr. landze. Vers-Sta. Ost., 3, 53; Abs. J. Soc. Chem. Ind., 378 (1900). 
In each case solution was effected by boiling with 30 to $50 \mathrm{cc}$. of concentrated nitric acid and 5 to Io cc. concentrated hydrochloric acid. The organic matter was not burned off before the solution nor was the silica removed by evaporation. The results obtained are shown in Table A which follows :

TABLE A. RESUITS WITH AND WITHOUT REPRECIPITATION.

\begin{tabular}{|c|c|c|c|c|}
\hline \multirow[b]{2}{*}{ No. } & \multirow[b]{2}{*}{ Description of sampl } & \multirow[b]{2}{*}{$\begin{array}{c}\text { Official } \\
\text { method. } \\
\text { e. } \\
\text { Per cent. } \mathrm{P}_{2} \mathrm{O}_{0} \text {. }\end{array}$} & \multicolumn{2}{|c|}{ Woy's method } \\
\hline & & & $\begin{array}{l}\text { as published. } \\
\text { Per cent. } \mathrm{P}_{2} \mathrm{O}_{5} \text {. }\end{array}$ & $\begin{array}{l}\text { omitting 2nd } \\
\text { precipitation } \\
\text { Per cent. } \mathrm{P}_{2} \mathrm{O}_{3}\end{array}$ \\
\hline I. & Mixed fertilizer & $\ldots \ldots$ Ir.J6 & I I. 13 & I [. I6 \\
\hline 2. & “ & $\ldots \ldots I 2.23$ & 12.26 & I 2.27 \\
\hline 3. & " & $\ldots \ldots \mathrm{I} 2.95$ & 12.84 & 13.02 \\
\hline 4. & “" & $\ldots \ldots$ II.I5 & I 1.26 & II.I I \\
\hline 5 . & “" & $\ldots .9 .80$ & 9.73 & 9.60 \\
\hline 6. & $\because$ & .... I0.84 & 10.95 & I0.93 \\
\hline 7 . & " & $\ldots . \times 10.53$ & 10.62 & 10.70 \\
\hline & Average.... . & $\ldots \ldots$ II.24 & II. 26 & II 26 \\
\hline
\end{tabular}

In these samples the second precipitation demanded by Woy's method seems to have been entirely unnecessary. We therefore tried the effects of salts of a few of the commoner acids and bases upon the results obtained by ignition of the first yellow precipitate. A commercial superphosphate was dissolved as above and its phosphoric acid content determined by the official method and by ignition of the first "yellow" precipitate. To aliquot parts of the same solution, corresponding to 0.4 gram of substance, were added the various salts, about 0.4 gram being used in each case. The yellow precipitate was ignited without reprecipitation. The determinations were not duplicated as in no case was the deviation from the true percentage greater than might easily be due to manipulation of a new method. The results are shown in Table B.

TABLH, B. EFFECTS OF IMPURITIES.

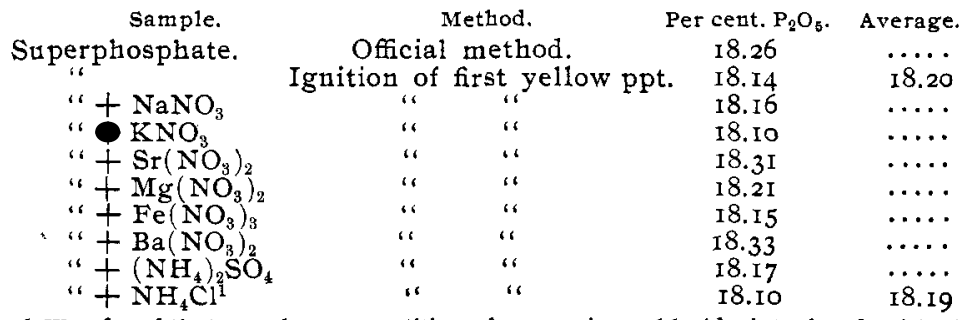

1 Woy found that very large quantities of ammonium chloride interfered with the precipitation of ammonium phosphomolybdate. 
In carrying out the method it was naturally found that the precipitate formed was more granular and more easily washed if the molybdate solution was added very slowly and with vigorous stirring. The modification which follows seems to us to combine most of the best features of Woy's and Gladding's methods.

\section{MODIFIED METHOD.}

To the solution representing 0.2 to 0.5 gram of the sample, add $25 \mathrm{cc}$. strong ammonia (sp. gr. 0.90), neutralize with nitric acid and then add 5 to $8 \mathrm{cc}$, according to the impurities present, of concentrated nitric acid (sp. gr. I.42) in excess. Bring the solution to a bulk of about $150 \mathrm{cc}$. and a temperature of $50^{\circ} \mathrm{C}$. and maintain at this temperature (conveniently by standing the beaker in a pan of warm water) while adding, drop by drop with constant stirring, a neutral 3 per cent. solution of ammonium molybdate sufficient to give an excess of about $20 \mathrm{cc}$. Stir vigorously and allow to stand for about ten minutes; decant through a porcelain Gooch crucible and wash the precipitate three times by decantation with 50 to $70 \mathrm{cc}$. and then on the filter with 200 to $250 \mathrm{cc}$. of a cold solution of one part concentrated nitric acid in roo parts of water. Finally the precipitate is ignited as described by Woy, leaving a residue of $\mathrm{P}_{2} \mathrm{O}_{5} .24 \mathrm{MoO}_{3}$.

Suction was employed in the filtration, and in washing on the filter the precipitate was well stirred up with the dilute acid wash solution. The neutral ammonium molybdate solution was employed simply to permit of the direct addition of the desired amount of nitric acid irrespective of the amount of the molybdate solution to be used.

As would be expected in working any new method, a few individual determinations were found on repetition to be wrong. These "wild" results were too high, doubtless from the precipitation of impurities, and emphasize the necessity of careful, slow addition of the molybdate solution. Only one sample was encountered in which the results obtained by the method described differed by more than two-tenths of one per cent. from those given by the official method. This was a phosphatic slag which contained, according to the official method, 17.27 per 
PHOSPHORIC ACID AS PHOSPHOMOLYBDIC ANHYDRIDE. 657

cent. and according to the new method 16.97 per cent. of $\mathrm{P}_{2} \mathrm{O}_{5}$. The final precipitate obtained by the official method was, however, contaninated with iron and this result was thus undoubtedly too high, that by the new method being probably nearer the truth. These results on this sample are therefore omitted from the table which follows.

Table $\mathrm{C}$ below shows the results obtained by Woy's method, omitting the second precipitation, and by the modified method described above, together with the results obtained by the official method. The samples are numbered in the order in which they were analyzed.

TABLE C. COMPARISON OF RESULTS.

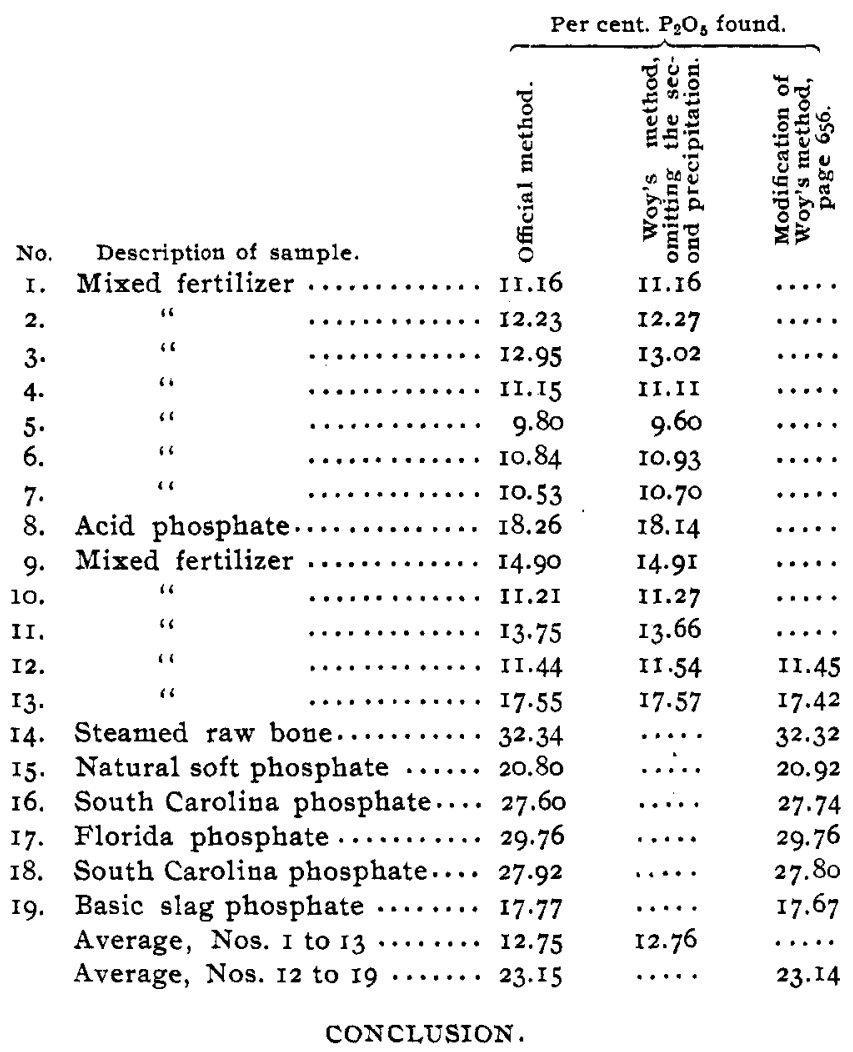

In all of the twenty samples examined, which represent a large I 7-22 
variety of the common phosphatic materials of the fertilizer industry, the determination of phosphoric acid as phosphomolybdic anbydride was found to give satisfactory results even without a reprecipitation of the ammonitum phosphomolybdate.

The presence in considerable quantity of some of the common acids and bases was found to be without appreciable effect.

With either modification of the method the average result obtained on all the samples analyzed was practically the same as that yielded by the official method which would seem to indicate that such variations as occur are due mainly to manipulation.

By the method described a determination may be completed in much less time than by any other gravimetric method with which we are familiar but in handling several samples simultaneously, the saving of time is less apparent.

Columbia Untrersity, New York City, July, igoo.

[CONTRibution From the Chemical Laboratory of The PennsylVANIA STATE COLLEGE.]

\section{THE ACTION OF SODIUM ALCOHOLATE UPON ANISYLI- DENE ACETOPHENONE DIBROIIIDE.}

By F. J. PONd ANd ARthur S. Shoffstali.

Received August 1, rooo.

I $\mathrm{N}$ a preceding communication ${ }^{1}$ on this subject it was mentioned that sodium methylate reacts with the dibromides of certain unsaturated ketones of the general formula,

$$
\mathrm{R}-\mathrm{CH}=\mathrm{CH}-\mathrm{CO}-\mathrm{C}_{6} \mathrm{H}_{5} \text {, }
$$

yielding $\mathrm{I}, 3$-diketones of the formula,

$$
\mathrm{R}-\mathrm{CO}-\mathrm{CH}_{2}-\mathrm{CO}-\mathrm{C}_{6} \mathrm{H}_{5} \text {. }
$$

Thus benzylidene acetophenone dibromide was readily converted into dibenzoyl methane, and anisylidene acetophenone dibromide was found to give a 1,3 -diketone analogous to dibenzoyl methane, and called anisoyl benzoyl methane. It was suggested that the formation of these diketones from the dibromides of unsaturated ketones was accomplished by the production of unsaturated ethers,

$$
\mathrm{R}-\mathrm{C}\left(\mathrm{OCH}_{3}\right)=\mathrm{CH}-\mathrm{CO}-\mathrm{C}_{6} \mathrm{H}_{5} \text {, }
$$

1 Pond, Maxwell, and Norman : This Journal, 11, 955. 